ISSN: 2637-4676

\title{
Environmental Accounting and Auditing and Eco mark
}

\author{
Ibsa Mussa ${ }^{1}$, Awel Feku² and Mohammed Mussa ${ }^{3 *}$ \\ ${ }^{1}$ Gara Mulata Referral Hospital, Oromia Health Office, Ethiopia \\ ${ }^{2}$ Bale Zone Pastoral and Agro-pastoral office, Oromia Pastoral Commissioner, Ethiopia \\ ${ }^{3}$ Department of Animal and Range Science, Ethiopia
}

Received: 此 November 12, 2018; Published: 制 November 20, 2018

*Corresponding author: Mohammed Mussa, Department of Animal and Range Science, Ethiopia

Summary

Environmental accounting is the identification, measurement and allocation of environmental costs, the integration of these environmental costs into business decisions, and the subsequent communication of the information to a company's stakeholders. Auditing environmental is essentially an environmental management tool for measuring the effects of certain activities on the environment against set criteria or standards. Eco mark is a certification mark issued to products conforming to a set of standards aimed at the least impact on the ecosystem. The paper has reviewed the environmental drawbacks associated with hydropower projects. It is amply clear that regulatory actions by pollution control agencies alone cannot restore the environment to its pristine state. Pro-active and promotional roles should also be geared up in harmony with the overall environmental protection strategy. The time has come for consumers to take the lead in prompting manufacturers to adopt clean and eco-friendly technologies and environmentally-safe disposal of used products, along with preventive and mitigate approaches. These are also discussed in the paper.

Keywords: Ecomark; Environmental accounting; Environmental auditing

\section{Introduction}

The environment is under tremendous stress from rapid industrialization, unplanned urbanization and changing consumption patterns in the race to achieve better living standards Alfsen \& Greaker [1] Samakovlis [2]. Today everyone is concerned with environmental issues as they influence all human activities. It is amply clear that regulatory actions by pollution control agencies alone cannot restore the environment to its pristine state. Pro-active and promotional roles should also be geared up in harmony with the overall environmental protection strategy Sing [3]. Considering the future environmental and energy scenarios, environmental management systems and ecomark is now recognized as a pre-requisite for sustainable development and eco-friendly environmental management in organizations. Environmental accounting is the identification, measurement and allocation of environmental costs, the integration of these environmental costs into business decisions, and the subsequent communication of the information to a company's stakeholders Hecht [4].
Environmental auditing is essentially an environmental management tool for measuring the effects of certain activities on the environment against set criteria or standards Penna [5]. It was originated in the United States in the 1970s, then after introduced to the UK and elsewhere mainly by multi-national companies who began to apply the audit procedures corporately and via subsidiaries Penna [5], Hecht [4]. Eco mark is a certification mark issued by the Bureau of Standards to products conforming to a set of standards aimed at the least impact on the ecosystem Huhtala [6] \& Samakovlis [2]. It is the mark that is attached on a product which is available in our daily lives as well as certified as contributing to environmental preservation in terms of less environmental burden. It is also aimed for the consumers to make an environmental friendly product choice, and also to consider the relation of life and environment Paritosh [7]. Achieving sustainable development and eco-friendly environmental management in organizations incorporating the environmental accounting, environmental auditing and ecomark is now recognized as a pre-requisite. Therefore, the purpose of this 
term paper is to review the environmental accounting and auditing as well as Eco mark.

\section{Environmental accounting}

Environmental accounting is the identification, measurement and allocation of environmental costs, the integration of these environmental costs into business decisions, and the subsequent communication of the information to a company's stakeholders Hecht [4]. Identification includes broad examination of the impact of corporate products, services and activities on all corporate stakeholders. After companies identify the impacts on stakeholders as far as they can, they measure those impacts (costs and benefits) as precisely as possible in order to permit informed management decision making Alfsen \& Greaker [1] Samakovlis [2]. Measurements might be quantified in physical units or monetized equivalents. After their environmental impacts are identified and measured, companies develop reporting systems to inform internal and external decision makers (Alfsen \& Greaker [1]. Organizations use environmental accounting for several reasons. According to Hecht [4], helping the managers to make decisions that will reduce or eliminate their environmental costs; tracking better environmental costs that may have been previously obscured in overhead accounts or otherwise overlooked; better understand the environmental costs and performance of processes and products for more accurate costing and pricing of products; broadening and improving the investment analysis and appraisal process to include potential environmental impacts; and supporting the development and operation of an overall environmental management system are the reason behind use of environmental accounting by the organizations.

\section{Environmental auditing}

Environmental auditing is essentially an environmental management tool for measuring the effects of certain activities on the environment against set criteria or standards [4,5]. Organizations of all kinds now recognize the importance of environmental matters and accept that their environmental performance will be scrutinized by a wide range of interested parties. These are used to help improve existing human activities, with the aim of reducing the adverse effects of these activities on the environment. An environmental auditor will study an organization's environmental effects in a systematic and documented manner and will produce an environmental audit report. There are many reasons for undertaking an environmental audit, which include issues such as environmental legislation and pressure from customers Paritosh [7]. Environmental auditing is carried out when a development is already in place, and is used to check on existing practices, assessing the environmental effects of current activities (ex post). Environmental auditing therefore provides a 'snap-shot' of looking at what is happening at that point in time in an organization Paritosh [7]; Hecht [4]. The International
Organization for Standardization (ISO) has produced a series of standards in the field of environmental auditing. These standards are basically intended to guide organizations and auditors on the general principles common to the execution of environmental audits Hecht [4].

\section{Eco mark}

Ecomark or Eco mark is a certification mark issued by the Bureau of Standards to products conforming to a set of standards aimed at the least impact on the ecosystem Sing [3]. The mark is issued to various product categories with the purposes of increasing awareness among the consumers towards reducing environment impact Matthews [8]. There are criteria for marking product as Eco Mark product based on the cradle to grave approach, i.e. from raw material extraction to manufacturing and to disposal Matthews [8]; Sing [3].

The basic criteria cover broad environmental levels and aspects, but are specific at the product level. A product is examined in terms of the following main environmental impacts Sing [3]: 1. That they have substantially less potential for pollution than other comparable products in production, usage and disposal [9]. That they are recycled, recyclable, made from recycled products or bio- degradable, where comparable products are not; 3 . That they make significant contribution to saving non-renewable resources including non-renewable energy sources and natural resources compared with comparable products [10]. That the product must contribute to a reduction of the adverse primary criteria which has the highest environmental impact associated with the use of the product, and which will be specifically set for each of the product categories.

\section{Conclusion}

Environmental accounting is analysis of environmental costs and the integration of these environmental costs into business decisions, and the subsequent communication of the information to a company's stakeholders for management and informed decision making. Environmental auditing is essentially an environmental management tool for measuring the effects of certain activities on the environment against set criteria or standards for improving existing human activities, with the aim of reducing the adverse effects of these activities on the environment. Ecomark is a certification mark issued by the Bureau of Standards to products conforming to a set of standards aimed at the least impact on the ecosystem. The mark is issued with the purposes of increasing awareness among the consumers towards reducing environment impact.

\section{References}

1. Alfsen K, Greaker M (2007) From natural resources and environmental accounting to construction of indicators for sustainable development. Ecological Economics 61: 600-610. 
2. Samakovlis E, Huhtala A, Bellander T, Svartengren M (2008) Valuing health effects of air pollution-focus on concentration-response functions. Journal of Urban Economics: 58(2): 230-249.

3. Singh AP, Raman NS, Waghe UP (2012) Ecomark scheme in Indi. Int J Pharm Med and Bio Sc 1(2): 1-12.

4. Hecht JE (2016) National Environmental Accounting: A Practical Introduction. International review of Environmental and Resource Economics 1(1): 3-66.

5. Penna RA (2006) Environmental Auditing: The Policy and the Prospects. The Environmental Forum 2(1): 16-20.

6. Huhtala A, Samakovlis E (2007) Air pollution, ill health and welfare. Environmental and Resource Economics 37: 445-463.
7. Paritosh CT (2014) Environmental Audit in Practice in India, IndoBritish Workshop on Environmental Impact and Risk Assessment of Petrochemical Industry and Environmental Audit. NEERI pp. 99-101.

8. Matthews E, Amann C, Bringezu S, Fischer Kowalski M, Weisz H (2006) The Weight of Nations ñ Material Out flows from Industrial Economies. World Resources Institute, Washington DC, USA.

9. Verbruggen H (2001) Calculations of Sustainable National Income According to Huetingís Methodology. In: van Ierland EC, J van der Straaten, Vollebergh HRJ (Eds.), Economic Growth and Valuation of the Environment, A Debate, Cheltenham, UK and Northampton, Edward Elgar Publishing, Massachusetts, USA.

10. Alien JD (2003) Environmental Auditing: Reaching the Bottom Line in Compliance. National Environmental Enforcement Journal 2(1): 3-14.

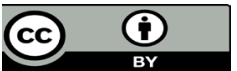

This work is licensed under Creative Commons Attribution 4.0 License

To Submit Your Article Click Here: $\quad$ Submit Article

DOI: 10.32474/CIACR.2018.05.000212

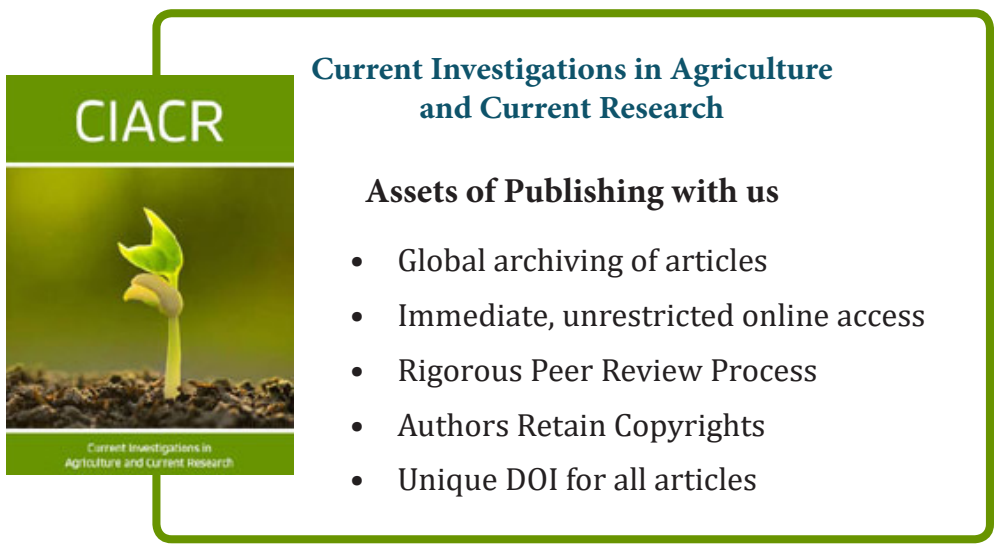

